\title{
Sobre a viabilidade da noção de conteúdo mental estreito
}

\author{
The viability of narrow content
}

\author{
Julia Telles de Menezes \\ Goethe-Universität Frankfurt, Alemanha \\ Orcid 0000-0003-1302-6077 \\ juliatelles@gmail.com
}

Resumo: No sentido relevante para a discussão filosófica, conteúdos são entidades abstratas que uma teoria semântica associa a proferimentos linguísticos e a atos de pensamentos. Ao caracterizar os estados cognitivos subjacentes aos atos de fala e de pensamento, essas entidades abstratas são utilizadas na interpretação da linguagem e das expressões do pensamento. Mediante o recurso aos conteúdos, nós visamos dar conta do desenvolvimento temporal desses estados cognitivos, do seu desdobramento em outros estados cognitivos e, eventualmente, em ações intencionais. O "cálculo" abstrato com os conteúdos visa explicar as inferências concretas teóricas $e$ práticas envolvendo os estados cognitivos. Muitos filósofos consideram plausível a tese segundo a qual o desenvolvimento dos estados cognitivos de um agente racional depende exclusivamente de suas propriedades intrínsecas. A isto corresponde a tese de que existe um conteúdo estreito que abstrai das relações que conectam o indivíduo ao meio ambiente natural e social. A discussão filosófica nas últimas décadas mostrou que é muito difícil ou talvez (como alguns preferem) impossível dar uma formulação satisfatória à noção de conteúdo estreito. Este é o problema geral em torno do qual giram as considerações apresenta- 
das neste trabalho. Em termos mais específicos, o objetivo do artigo é motivar a reconsideração da posição internalista do conteúdo mental para dar conta de problemas o conhecimento introspectivo, causação mental e enigmas da racionalidade.

Palavras-chave: Externalismo; Internalismo; Conteúdo Mental.

Abstract: In the relevant philosophical sense, contents are abstract entities that a semantic theory usually associates with utterances and thought acts. These abstract entities are used in the interpretation of language and thought when the cognitive states underlying speech acts and thoughts are specified. We resort to contents in order to account for temporal development of these cognitive states, its unfolding into other cognitive states and, eventually, in intentional acts. This abstract "calculus" involving contents aims at explaining the practical and theoretical inferences involving cognitive states. Many philosophers consider it to be plausible the thesis that says that the development of the cognitive states of a rational agent depends entirely on his intrinsic properties. This plausibility corresponds to the thesis that there is a narrow mental content that abstracts away the relation that an individual maintains to its social and natural environment. The philosophical discussion in the last decades shown that it is difficult or perhaps (as some of the philosophers might prefer to say) impossible to give a satisfactory formulation to the notion of narrow content. Specifically, my goal is to motivate the rehabilitation of internalism as a compelling position in order to account for mental causation problem, introspective knowledge and puzzles of rationality.

Keywords: Externalism; Internalism; Mental Content.

\section{Introdução}

O presente artigo trata de questões características de um núcleo importante da filosofia da mente: a teoria do conteúdo. No sentido relevante para a discussão filosófica, conteúdos são entidades abstratas que uma teoria semântica associa a proferimentos linguísticos (sobretudo asserções) e a atos de pensamentos (sobretudo crenças). Ao caracterizar os estados cognitivos subjacentes aos atos de fala e de pensamento, essas entidades abstratas são utilizadas na interpretação da lingua- 
gem e das expressões do pensamento. Mediante o recurso aos conteúdos, nós visamos dar conta do desenvolvimento temporal desses estados cognitivos, do seu desdobramento em outros estados cognitivos e, eventualmente, em ações intencionais. $\mathrm{O}$ "cálculo" abstrato com os conteúdos visa explicar as inferências concretas teóricas e práticas envolvendo os estados cognitivos. Muitos filósofos consideram plausível a tese segundo a qual o desenvolvimento dos estados cognitivos de um agente racional depende exclusivamente de suas propriedades intrínsecas. A isto corresponde a tese de que existe um conteúdo estreito que abstrai das relações que conectam o indivíduo ao meio ambiente natural e social, isto é, um conteúdo que depende, no que diz respeito à sua individuação, somente do que é interno ao sujeito individual dos estados mentais aos quais ele é atribuído. A discussão filosófica nas últimas décadas mostrou que é muito difícil ou talvez (como alguns preferem) impossível dar uma formulação satisfatória à noção de conteúdo estreito.

Este é o problema geral em torno do qual giram as considerações apresentadas neste artigo. Em termos mais específicos, o objetivo do artigo é a motivação da reconsideração da posição internalista a respeito do conteúdo mental.

\section{Determinação do conteúdo mental: internalismo vs. Externalismo}

É importante separar analiticamente (i) o conteúdo e a sentença, e (ii) o conteúdo e os fatos representados. A primeira distinção torna-se óbvia quando se considera o fato de que diferentes sentenças em idiomas diferentes, mas também no mesmo idioma, podem representar o mundo da mesma maneira, isto é, podem ter o mesmo conteúdo. Por exemplo, "It rains", "Es regnet" e "Il pleut" representam o mundo da mesma maneira: o conteúdo dessas sentenças é também o da sentença "Está chovendo." A segunda distinção deve ser feita para dar conta do caso em que sentenças representam inveridicamente o mundo. Também essas sentenças-que transmitem informações falsas-têm significado: elas dizem alguma coisa sobre o mundo, mesmo que o que elas digam não seja verdadeiro. $\mathrm{O}$ 
conteúdo é, portanto, uma entidade abstrata entre as sentenças "concretas" e os fatos do mundo. Muitos filósofos chamam essas entidades abstratas de "proposições." Os fatos do mundo correspondem às proposições verdadeiras. A correspondência é tão estreita que alguns filósofos identificam fatos com proposições verdadeiras. Se estados de coisas são fatos possíveis, isto é, modos possíveis (mas não atuais) de existência das coisas do mundo, então o conteúdo pode ser visto como estado de coisas. Estados de coisas são fatos possíveis e fatos são estados de coisas atuais (reais).

A proposição não determina a verdade da sentença da qual ela é o conteúdo. Somente a inspeção dos fatos do mundo pode determinar o valor de verdade da sentença. Eventualmente, a proposição corresponde a um fato, mas é preciso ir além da proposição para determinar se a sentença é verdadeira. Embora não determine o valor de verdade, a proposição ou o conteúdo especifica as condições nas quais a sentença seria verdadeira, ou seja, o conteúdo é um objeto abstrato que é ou possui um conjunto de condições de verdade.

As teorias sobre o conteúdo linguístico podem ser estendidas e aplicadas aos estados mentais. Pelo menos alguns estados mentais têm conteúdo. Dentre eles as crenças por exemplo possuem conteúdo que deve ser também definido em termos de condições de verdade. Portanto, de forma similar ao caso do conteúdo linguístico, o conteúdo mental é também definido extensionalmente em termos de condições de verdade. Se o conteúdo de uma sentença declarativa é representado pelas condições nas quais a sentença é verdadeira, o conteúdo de uma crença deve ser representado pelas condições nas quais a crença é verdadeira: a crença será verdadeira se o mundo for da forma como ela o representa.

A essa analogia entre conteúdo de sentenças e conteúdo mental subjaz a idéia de uma linguagem do pensamento: se a linguagem natural consiste, segundo as teorias do significado predominantes, na relação entre sentenças, proposições e fatos representados, a linguagem do pensamento consiste na relação entre "sentenças mentais", seu conteúdo e os fatos extra- 
-mentais representados. Se as sentenças da linguagem são, por exemplo, inscrições no papel ou sequências de sons utilizadas como representações do mundo, as sentenças mentais são configurações do sistema nervoso que, pelo papel mediador que elas desempenham entre as ocorrências do mundo externo e o comportamento do organismo, têm a propriedade de representar estado de coisas no mundo.

Apesar do caráter abstrato que a noção de conteúdo possui, podemos notar seu apelo intuitivo na explicação da forma como interagimos com pessoas, compreendemos indivíduos, nos comunicamos, prevemos o comportamento dos organismos. Todas essas práticas essenciais à vida em grupo pressupõem a atribuição de estados mentais. $\mathrm{E}$ a individuação destes estados mentais é feita mediante o seu conteúdo. É assim que dizemos, por exemplo, "Joana quer ir à Opera na quinta-feira." Há três elementos envolvidos nessa atribuição: o indivíduo (o sujeito do estado mental), a atitude atribuída a ele e o conteúdo da atitude em questão. Tais atribuições são parte de um sistema poderoso que utilizamos cotidianamente na coordenação de nossas atividades comuns, um sistema que nos possibilita descrever a mente dos outros, bem como a nossa própria mente. É este sistema que os filósofos da mente chamam de "Psicologia Popular" (Folk Psychology). Como o papel central nesse sistema é desempenhado pelo conteúdo, a psicologia popular é uma psicologia baseada em conteúdo.

Independente de outras funções que possa ter a atribuição de estados mentais de acordo com o sistema da psicologia popular, ela serve à explicação e previsão do comportamento para fins da coordenação de nossas atividades. É plausível, embora não aceito por todos, que a explicação relevante nesse caso seja causal. Isso quer dizer que os estados mentais mencionados na psicologia popular são concebidos, pelo menos por muitos filósofos, como antecedentes causais do com- portamento (intencional). Ademais, o conteúdo é uma propriedade essencial dos estados mentais da psicologia popular. E estados mentais são individuados mediante o seu conteúdo. Então, o conteúdo mental deve ser causalmente relevante. É em virtude dos conteúdos envolvidos que o "silogismo prático" é uma explicação válida da 
sua conclusão: $\mathrm{X}$ deseja que $\mathrm{p}$ seja o caso. $\mathrm{X}$ acredita que a realização de q é um meio eficaz para a realização de p. Portanto, na ausência de outras razões, $X$ age no sentido de realizar $q$. De acordo com a interpretação do silogismo prático como uma explicação causal, as relações entre os conteúdos p e q geram causalmente o comportamento descrito na conclusão.

Conteúdos mentais são entidades abstratas determinadas por configurações concretas. Na terminologia da filosofia da mente, conteúdos mentais sobrevêm a estados físicos. A posição inicial—para muitos filósofos: a única posição plausível-considera que a base de superveniência dos conteúdos mentais é constituída exclusivamente pelos estados físicos intrínsecos ao organismo ao qual o estado mental e o conteúdo correspondente são atribuídos. O conteúdo dependeria, de acordo com essa posição, somente da configuração física interna do organismo. Os poderes causais do conteúdo seriam, assim, herdados dos poderes causais dos estados físicos internos. Em oposição a esse internalismo sobre o conteúdo mental, o externalismo amplia, por assim dizer, a base de superveniência: o conteúdo mental é determinado também por configurações físicas externas ao organismo.

O experimento de pensamento de Putnam, o chamado argumento da Terra Gêmea ${ }^{1}$ (Putnam 1975), mostra que o con-

$1 \quad \mathrm{O}$ argumento consiste na concepção de um planeta semelhante à nossa Terra, a Terra Gêmea. A Terra e a Terra Gêmea têm características superficiais idênticas. A única diferença relevante entre os dois ambientes é que na Terra o termo "água" é utilizado para designar $\mathrm{H} 2 \mathrm{O}$, ao passo que, na Terra Gêmea, o termo ortograficamente idêntico "água” designa XYZ. H2O e XYZ são substâncias diferentes que partilham as mesmas características superficiais. Putnam pede que concebamos um habitante da Terra e seu sósia na Terra Gêmea, qualitativamente idêntico a sua contra-parte na Terra. A situação é concebida de tal forma que os sósias-que usam a forma "água" para fazer referência à "substância aquosa" em seus respectivos mundos-têm o mesmo conteúdo descritivo nas suas mentes: "líquido, incolor, inodoro, que forma rios e lagos etc." A questão crucial levantada por Putnam é se os sósias, quando proferem sentenças contendo a forma "água," estão falando da mesma coisa, isto é, se a forma "água" tem o mesmo significado para o habitante da Terra Gêmea e para o habitante da nossa Terra. Segundo Putnam, os sósias não estão falando da mesma coisa quando utilizam sentenças contendo a forma "água." Habitantes da Terra estão falando de $\mathrm{H} 2 \mathrm{O}$, ao passo que habitantes da Terra Gêmea estão falando de XYZ, independentemente das descrições associadas à forma "água" em suas mentes individuais. 
teúdo dos termos proferidos por um falante competente é determinado, pelo menos parcialmente, por aspectos objetivos do meio ambiente onde o falante está situado. Isso vale, sobretudo, para os termos que designam espécies naturais. O internalismo semântico, contra o qual Putnam argumenta, é a posição que defende que, apesar do caráter público da proposição expressa por sentenças (sentido fregeano), a compreensão dessas entidades abstratas-proposições-é um ato psicológico que ocorre "na cabeça." É nesse sentido que a tradição descritivista fregeana é considerada individualista por Putnam. A conclusão de Putnam a partir do argumento da Terra Gêmea é que o que fixa a referência dos termos em questão não é o conteúdo descritivo paradigmaticamente associado ao termos que o falante emprega, pois esse é o mesmo conteúdo para os dois falantes (um falante na Terra e um na Terra Gêmea), mas aspectos externos à vida psicológica individual do sujeito. O que fixa a referência da palavra "água", em última instância, é a natureza microscópica objetiva do líquido incolor e inodoro que forma rios e lagos etc., via a divisão do trabalho linguístico entre especialistas e não-especialistas que identificam a natureza microscópica relevante como $\mathrm{H} 2 \mathrm{O}$, num caso, e XYZ, no outro. Assim, pelo menos o conteúdo de sentenças contendo termos de espécies naturais seria amplo (não-individualista), uma vez que é determinado por configurações externas aos falantes individuais.

A consequência mais importante do experimento de Putnam, para os propósitos do presente artigo, é a violação da tese da superveniência local, ou seja, o conteúdo dos estados mentais não sobrevém aos estados intrínsecos do indivíduo. Os doppelgängers são fisicamente idênticos, mas suas crenças são diferentes. O conteúdo é determinado, pelo menos parcialmente, por propriedades micro-estruturais do mundo onde a palavra "água" é proferida.

\section{Sobre a noção de conteúdo estreito}

Inicialmente, existem duas posições sobre a individuação dos conteúdos mentais. O conteúdo estreito é concebido como o conteúdo individuado exclusivamente por proprieda- 
des intrínsecas ao sujeito. O conteúdo amplo é concebido como o conteúdo individuado também por propriedades relacionais. Assim, o conteúdo amplo seria relevante para a explicação do comportamento descrito intencionalmente em termos dos aspectos naturais e sociais dos agentes situados. É um fato que o comportamento é às vezes descrito nesses termos. O conteúdo estreito seria relevante para a caracterização da contribuição individual ao comportamento, concebida em abstração do contexto. Pode não ser óbvio que exista uma descrição intencional do comportamento que não leve em conta o contexto, isto é, que essa contribuição individual possa ser isolada. Os internalistas afirmam, porém, que esse nível de descrição é pressuposto nos vários experimentos de pensamento que motivaram a introdução do conteúdo amplo. Afinal de contas, os sósias na situação imaginada por Putnam agem da mesma maneira em um certo sentido. Em outro sentido, eles agem diferentemente. Para explicar o comportamento comum aos sósias, devemos atribuir-lhes conteúdos partilhados. O princípio relevante aqui diz que efeitos iguais são produzidos por causas iguais. Se assumirmos que o comportamento comum aos sósias é ainda intencional, as causas relevantes são estados mentais conteudísticos. E o conteúdo imprescindível para a explicação do comportamento é, nesse caso, estreito.

Portanto, a investigação sobre a natureza dos estados mentais está conectada à questão sobre a atribuição de conteúdo, bem como à questão sobre a eficácia causal dos conteúdos mentais e como estes são individuados. Além disso, explicar inferências racionais entre pensamentos (processos mentais) é um ponto crucial que qualquer teoria do conteúdo mental deve abordar.

Apesar de intuitiva num primeiro momento, devemos admitir que, à luz do argumento de Putnam, a noção de conteúdo estreito torna-se bastante controversa. Isto ocorre porque, ao definirmos conteúdo em termos de condições de verdade, apelamos a outra intuição, a saber: conteúdos definidos em termos de condições de verdade parecem ser, por definição, amplos, já que, para explicitar as condições de verdade em questão mobilizamos um vocabulário que contém termos que fazem referência ao mundo externo do indivíduo. Assim, torna-se menos evidente 
de que modo a crença cujas condições de verdade são expressas por "A neve é branca" pode ser determinada exclusivamente por propriedades intrínsecas do sujeito, já que "neve" designa algo que não depende do que o sujeito pensa ou da descrição que ele associa em sua mente a esse termo, mas de aspectos do mundo. É neste sentindo que os opositores da noção de conteúdo estreito afirmam que o conteúdo estreito não pode ser conteúdo, pois não admite definição em termos de condições de verdade. No entanto, veremos alguns dos argumentos mais importantes a favor da necessidade e viabilidade do conteúdo estreito.

\subsection{Argumento Causal}

Em linhas gerais, o argumento causal desenvolvido por Fodor (1987) gira em torno do problema da explicação causal do comportamento mediante o conteúdo de nossos estados mentais. O argumento causal é estruturado do seguinte modo: (i) estados mentais são introduzidos como fatores que explicam causalmente o comportamento. E é em virtude dos seus conteúdos que os estados mentais causam o que causam. Parece que nos comportamos de certa maneira por causa do que desejamos, do que acreditamos, do que esperamos etc. Esse é o caso do comportamento intencional. (ii) É plausível a tese segundo a qual os poderes causais de uma entidade devem ser propriedades internas da entidade em questão (tese da causação local). Os sósias imaginados por Putnam compartilham propriedades intrínsecas: eles são idênticos "molécula por molécula." Eles devem, portanto, compartilhar também os poderes causais. De acordo com a tese da causação local, conteúdos individuados amplamente não são causalmente eficazes. (iii) As premissas levariam à conclusão: ou bem conteúdos são causalmente inúteis, ou bem uma noção de conteúdo individuado não-relacionalmente é necessária para explicar o comportamento intencional. Isto é, se a tese da causação local estiver correta, considerações sobre poderes causais e propriedades intrínsecas do indivíduo levam à rejeição do externalismo.

No que concerne à primeira premissa, existe um sentido relevante no qual os comportamentos dos sósias são idênticos e 
aparentemente independentes da diferença do conteúdo representacional amplo de seus estados mentais. Assim, se pedimos um copo de água aos sósias, ambos agirão da mesma maneira, ou seja, realizarão a mesma ação. Sob a suposição de que essa ação comum é ainda intencional, nós precisamos de estados conteudísticos partilhados pelos sósias para a sua explicação. O conteúdo partilhado deve ser, obviamente, estreito. Parece que a distinção entre água e água gêmea que o argumento da Terra Gêmea supõe é causalmente irrelevante na explicação do comportamento comum dos sósias. Ao avaliar os poderes causais dos estados mentais e os poderes causais dos estados cerebrais dos sósias, nota-se que ambos possuem propriedades com os mesmos poderes causais e, por isso, são causalmente relevantes. As diferenças nas propriedades relacionais de estados mentais, ao contrário, são irrelevantes para os poderes causais. A força desse argumento depende, é claro, da suposição de que existe ainda um comportamento intencional comum aos sósias.

Uma possível objeção a esta premissa seria a de que os estados mentais dos sósias não têm os mesmos poderes causais, pois os comportamentos resultantes são diferentes. Quando pedimos a Oscar um copo de água, ele trará água (H2O), ao passo que, quando pedimos a Oscar Gêmeo um copo de água, ele trará água-g (XYZ). As ações dos sósias são dirigidas a entidades diferentes. O conteúdo do pensamento dos sósias produz efeitos distintos, pois os objetos proposicionais de suas ações intencionais são diferentes (o objeto proposicional do estado mental de Oscar envolve água; o de Oscar gêmeo, água-g).

A resposta de Fodor (1987) a esta objeção é que poderes causais devem ser avaliados "transversalmente a contextos" (across-contexts). Em oposição a esta forma de avaliar, temos a avaliação "dentro de contextos" (within contexts). Fodor nota que devemos distinguir duas descrições intencionais dos comportamentos dos sósias. De acordo com uma descrição, os comportamentos, quando considerados como efeitos dos pensamentos dos sósias, são de fato diferentes, pois o conteúdo de seus pensamentos, isto é, de suas atitudes proposicionais são diferentes. Segundo a outra descrição, os comportamentos dos sósias são idênticos. Mas nesse caso, os poderes causais estão sendo ava- 
liados dentro de contextos, o que é, como Fodor quer mostrar, a maneira inadequada de avaliar poderes causais. A identidade relevante dos comportamentos dos sósias aparece quando os poderes causais dos conteúdos são avaliados transversalmente.

O meu pensamento (na Terra) "eu quero tomar água" me leva a buscar água (H2O). O pensamento do meu sósia (na Terra Gêmea) "eu quero tomar água" tem como resultado uma outra ação, a ação de buscar água-g (XYZ). As ações resultantes, isto é, os efeitos dos (conteúdos dos) pensamentos são diferentes-pelo menos quando as ações são descritas dessa forma, isto é, amplamente. Mas não se pode inferir imediatamente do fato de que os efeitos são diferentes que as causas são diferentes (supondo que se pode fazer uma distinção entre a causa e o contexto, o mesmo evento num outro contexto terá efeitos distintos). Tampouco pode-se inferir daí que os poderes causais dos pensamentos em questão são diferentes. Por certo, a manifestação do poder causal do pensamento "eu quero tomar água" é diferente nos dois contextos. Isto quer dizer que há, inicialmente, dois fatores aos quais poderia ser atribuída a diferença nos efeitos: os poderes causais, por um lado, e os contextos onde os poderes causais se manifestam, por outro. A solução de Fodor consiste na afirmação de que, apesar da diferença nos conteúdos amplos, os poderes causais do pensamento expresso por "eu quero tomar água" são os mesmos. É a diferença nos contextos de proferimento da sentença que leva a resultados diferentes. Isto leva Fodor a afirmar que o conteúdo amplo é uma função de pensamentos a extensões e o conteúdo estreito é uma função de pensamentos e contextos a extensões. Como os poderes causais entram na individuação dos conteúdos explanatoriamente relevantes, as propriedades que individuam os conteúdos são as mesmas propriedades que conferem ao pensamento poderes causais. $\mathrm{O}$ argumento causal defende que o conteúdo causalmente relevante é estreito.

Quando a forma "água" ocorre no pensamento do terráqueo, ela se refere a $\mathrm{H} 2 \mathrm{O}$ e quando a mesma forma "água" ocorre no pensamento do sósia, ela se refere a XYZ. Mas essa diferença é irrelevante para a questão sobre a identidade de poderes causais, pois estas formas estão sendo empregadas em 
contextos distintos. A avaliação transversal envolve colocar contrafactualmente os dois pensamentos no mesmo contexto:

(a) if his thoughts had occurred in my context, it would have had the effects that my thought did have; and (b) if my thought had occurred in his context, it would have had the effect that his thought did have. For our thoughts to have the same causal powers both of those counterfactuals have to be true. (Fodor, 1987, p. 35)

O teste da avaliação transversal consiste na avaliação dos efeitos que os pensamentos produziriam se estivessem no mesmo contexto. A posição de Fodor é apenas a de que precisamos levar em consideração o contexto de instanciação dos poderes causais para avaliá-lo. Fodor mostra que a desconsideração do contexto na avaliação dos poderes causais leva a resultados absurdos:

This, surely, is the intuitively natural way to compare causal powers. Consider:

- "Cats raised in Manhattan unable to climb trees" top scientist says.

-Why, that's rather disturbing. How do you explain it?

-There aren't any trees in Manhattan for them to climb.

$-\mathrm{Oh}$.

(Fodor, 1991, p. 8, n. 4)

A diferença no comportamento dos sósias reflete também o conflito entre dois princípios mobilizados na atribuição de estados mentais, a saber: o princípio da boa vontade interpretativa e o princípio da humanidade. De acordo com o princípio da boa vontade interpretativa, nós atribuímos estados mentais a outras mentes pressupondo que as crenças das outras mentes sejam majoritariamente tão verdadeiras e razoáveis quanto as nossas. Isso exige, inter alia, a consideração do ambiente do indivíduo e a atribuição dos estados mentais de acordo com o ambiente do indivíduo, mas à luz dos nossos próprios pensamentos, tomando como ponto de partida, portanto, o nosso ambiente. Se interpretamos o pensamento do sósia expresso por "A água é molhada" à luz do nosso próprio contexto, isto é, de acordo com o princípio da boa vontade interpretativa, temos de atribuir ao sósia da Terra Gêmea a crença de que a 
água-g é molhada, pois qualquer outra atribuição faria desse pensamento um pensamento irracional. Esta atribuição divergente é requerida pelo princípio da boa vontade interpretativa. Não podemos atribuir ao sósia da Terra Gêmea o mesmo conteúdo que o nosso, já que nossos contextos são diferentes. Isto significa que os pensamentos dos sósias são distintos e que, portanto, seus comportamentos são também distintos.

O princípio da humanidade, por outro lado, enuncia que a atribuição de estados mentais é realizada quando nos colocamos na mesma posição do indivíduo que estamos interpretando. A pergunta crucial a se fazer, segundo este princípio é: o que nós pensaríamos se estivéssemos na mesma situação do sujeito que estamos interpretando? Isso seria equivalente à avaliação transversal de poderes causais, pois estamos interpretando o pensamento do sósia a partir do seu contexto, para o qual nos transportamos na imaginação. Isso é compatível, também, com a defesa do conteúdo estreito, pois como as considerações acima revelam, se os sósias estivessem no mesmo contexto, eles teriam os mesmos pensamentos (cf. Branddon-Mitchell e Jackson, 1996, p. 232).

A segunda premissa diz respeito à natureza local (McGinn, 1989) da relação de causação. Plausivelmente, os elementos que estão no nexus causal devem ser contíguos, em última instância. A relação de causação entre uma causa e um efeito distais é sempre mediada por relações causais proximais. Segundo a causação local, uma propriedade $\mathrm{F}$ de um evento c é causalmente relevante para a propriedade $\mathrm{G}$ do evento e se e somente se $\mathrm{F}$ for uma propriedade intrínseca de c. Como poderiam estados conteudísticos ter efeitos em virtude das relações extrínsecas que os constituiriam? Para os internalistas, essa pergunta já contém a sua resposta (negativa). Os externalistas, ao contrário, responderiam positivamente. O ônus da prova, neste caso, parece caber ao externalista, que deve demonstrar a falsidade da tese da causação local. Contudo, Fodor crê que é possível antecipar as dificuldades da posição externalista.

Fodor insiste que a individuação dos poderes causais para efeitos de teorização científica leva em conta somente as propriedades intrínsecas dos objetos. Conteúdos amplos não 
dependem apenas de propriedades intrínsecas do organismo. Disso segue que o externalismo, aliado ao princípio da causação local, implica a tese do epifenomenalismo dos estados mentais individuados amplamente. Para evitar o epifenomenalismo, ou bem abandonamos a tese externalista, ou bem abandonamos a ideia da individuação cientificamente adequada dos poderes causais. Se além de rejeitar a tese externalista, nós também aceitamos que não existem conteúdos estreitos, teremos de abandonar de vez a idéia de uma psicologia causal (científica) baseada em conteúdo mental (content-based psychology).

Deve ficar claro, neste ponto, o conflito entre conteúdo e causalidade sob a ótica do externalismo a respeito do conteúdo mental. Fodor afirma que, mesmo que se aceite a hipótese da individuação ampla dos conteúdos mentais, ela não serve aos propósitos da psicologia científica. Se assumirmos o externalismo, violamos o princípio de uma teoria científica, a saber: não postular entidades teóricas epifenomenais (McGinn, 1989). Diante desta incompatibilidade e implausibilidade natural de uma psicologia puramente sintática, o conteúdo estreito seria a alternativa plausível para dar conta da explicação causal do comportamento.

\subsection{Argumento do acesso introspectivo}

Uma assunção bastante comum na literatura da filosofia da mente diz que nós temos acesso direto ao conteúdo proposicional dos nossos estados mentais (a tese nao é a de que nós temos acesso a todos os conteúdos dos nossos estados mentais, já que existem estados mentais não proposicionais). De acordo com esse modo de ver não precisamos, em condições normais, recorrer a propriedades extrínsecas do mundo para sabermos no que acreditamos ou o que desejamos. Essa capacidade de perceber o conteúdo dos nossos estados mentais sem recorrer aos aspectos externos é chamada por muitos filósofos de introspecção. Portanto, se nós tivermos de fato acesso introspectivo ao conteúdo dos nossos estados mentais, nós somos capazes de distinguir entre dois pensamentos com conteúdos diferentes. De acordo com a interpretação externalista do experimento da Terra Gêmea, a distinção entre os pensamentos de Terráqueos e das suas contra-partes não parece estar disponível a eles via 
introspecção: a diferença no conteúdo é determinada relacionalmente e evidentemente o agente não tem acesso introspectivo ao seu ambiente --as coisas com as quais ele está relacionado. Por isso, pelo menos prima facie, e aceitando a tese da introspecção, há uma incompatibilidade entre o externalismo e o conhecimento ordinário que nós temos dos nossos próprios estados mentais. Aparentemente, somente o conteúdo estreito dos nossos estados mentais-se existir conteúdo estreitopode ser objeto da cognição direta introspectiva. Não temos acesso à micro-estrutura da substância aquosa do nosso meio ambiente via introspecção, mas somente através de recursos empíricos: a descoberta de que água é $\mathrm{H} 2 \mathrm{O}$ é uma descoberta empírica. Como diz McGinn: "World-dependence implies imperfect vision by the introspective eye" (MCGINN, 1989, p. 26).

Esse mesmo resultado pode ser alcançado com base em considerações contrafactuais sobre a mudança de ambiente entre a Terra e a Terra Gêmea (switching cases). Suponhamos que o terráqueo é transportado para a Terra Gêmea. Inicialmente, os pensamentos que ele expressa com a palavra "água" serão ainda sobre $\mathrm{H} 2 \mathrm{O}$. Gradualmente, porém, à medida que o terráqueo interage mais e mais com XYZ e deixa de interagir com $\mathrm{H} 2 \mathrm{O}$, seus pensamentos transformar-se-ão em pensamentos sobre XYZ. O conteúdo amplo dos pensamentos do terráqueo tornar-se-á, com o tempo, diferente do conteúdo amplo dos seus pensamentos antes de sua chegada à Terra Gêmea. A questão é se o terráqueo não perceberia essa mudança no conteúdo de seus pensamentos. É plausível supor que, do ponto de vista subjetivo, o agente não perceba nenhuma alteração. Parece, então, que o conteúdo a que nós temos acesso introspectivo não pode ser amplo-se nós tivermos de fato acesso introspectivo ao conteúdo dos nossos pensamentos. Este argumento sugere, portanto, que precisamos de uma noção de conteúdo estreito para capturar o tipo de conteúdo inalterado ao qual temos acesso introspectivo.

\subsection{Argumento da racionalidade}

Uma perspectiva que considera apenas a noção de conteúdo amplo não dá conta da informatividade de enunciados de identidade de termos co-extensionais, numa perspectiva se- 
mântica. O núcleo deste argumento é o enigma proposto por Kripke (1979). Nele Kripke observa que as críticas feitas à concepção simplificada do significado de Mill também podem ser atribuídas às outras teorias do significado, como a teoria Frege-Russell e a teoria da referência direta do próprio Kripke.

Kripke vê pelo menos duas evidências a favor da falha na concepção simplificada da linguagem. Primeiramente, uma razão para que a primeira ocorrência do nome "Hesperus" na sentença "Hesperus é Hesperus" não possa ser substituído pelo nome co-extensional "Phosporus" é que a sentença resultante ("Hesperus é Phosporus") expressa uma verdade a posteriori, ao passo que "Hesperus é Hesperus" é um caso de necessidade a priori. A concepção simplificada da linguagem não dá conta dessa diferença. Em segundo lugar, nomes próprios não podem ser substituídos salva veritate em contextos epistêmicos. Um falante competente pode acreditar que Hesperus é Hesperus, mas não que Hesperus é Phosphorus.

O problema para a teoria de Kripke aparece quando se considera não a substituição, em contextos intensionais, de um nome por uma descrição, mas a substituição de um nome por outro nome co-extensional. Outro clássico experimento de pensamento proposto por Kripke é o caso de Pierre. Pierre é um falante competente da língua francesa que sempre ouviu falar da famosa cidade que ele e os falantes a sua volta chamam de Londres. Pierre aprendeu através de descrições, sem ter saído da França, alguns fatos sobre Londres, e por isso está inclinado a dizer

(1) Londres est jolie.

Com base no proferimento sincero de Pierre, pode-se afirmar que:

(2) Pierre acredita que Londres é bonita.

Um dia Pierre se muda para uma área de Londres não muito atraente. Pierre aprende inglês, não pelo tradicional método de tradução, mas por imersão cultural, interagindo com seus vizinhos. Assim, Pierre não sabe que a cidade sobre a qual ele ouvia falar quando estava na França é a mesma cidade onde ele foi morar, que ele e os falantes a sua volta chamam de London. Pierre associa a Londres descrições diferentes, visto que 
ele teve conhecimento de Londres via dois canais de informações distintos. Suas impressões pessoais o levam a adquirir a crença que ele expressa com a sentença

(3) London is ugly.

Pierre endossa ainda a crença expressa pela sentença (2) por não saber que a cidade que ele chama de "London" e a cidade que ele chama de "Londres" denotam a mesma cidade. De acordo com a teoria da referência direta de Kripke, os objetos das crenças de Pierre são proposições singulares sobre a cidade designada rigidamente pelos nomes próprios "Londres" e "London." As proposições em questão não são sobre os nomes ou as descrições associadas a eles na mente de Pierre. Mas nesse caso, Pierre teria crenças contraditórias: que a mesma cidade é bonita e feia.

Para solucionar o enigma de Kripke, precisamos de uma teoria que assinale que as crenças, aparentemente contraditórias, que Pierre possui são diferentes devido à diferença em seus conteúdos. Se apenas o conteúdo amplo é mobilizado na atribuição das crenças expressas por cláusulas contendo os nomes "London" e "Londres," Pierre teria duas crenças contraditórias, o que caracterizaria um caso de irracionalidade. Contudo, se as crenças de Pierre são descritas em termos de conteúdo estreito, seria possível atribuir a Pierre duas crenças distintas, pois as crenças expressas por cláusulas contendo os nomes "London" e "Londres" teriam conteúdos estreitos diferentes.

Assim, a noção de conteúdo estreito seria útil para a explicação de ambos fenômenos descritos aqui, a explicação causal do nosso comportamento e para salvar do veredito Pierre de irracionalidade. Embora os argumentos explicitados acima estejam a favor da noção de conteúdo estreito, a evidência mais forte contra tal noção é que ela viola a própria definição e conteúdo mental ou linguístico, a saber, que qualquer noção de conteúdo precisa ser definida em termos de condições de verdade, o que torna o conteúdo necessariamente externalista. Diante desta evidência, ou abandonamos completamente a noção de conteúdo estreito ou a acomodamos em um esquema formal que preserve o componente externalista do conteúdo em questão. 


\section{Conclusão}

O presente artigo consistiu na exposição do debate entre o internalismo e o externalismo a respeito de conteúdos mentais. Os argumentos reproduzidos são fortes argumentos a favor da noção de conteúdo estreito. Evidentemente eles dependem de certas assunções que podem e até mesmo foram contestadas na literatura correspondente. Ainda assim, considerando a plausibilidade, pelo menos prima facie, dessas premissas e também a defesa enfática dessas premissas por filósofos relevantes, os argumentos são suficientemente fortes. Em alguns casos, eles operam negativamente, revelando os problemas que uma perspectiva externalista ainda teria de resolver. De fato, alguns filósofos externalistas aceitaram o desafio e elaboraram respostas interessantes aos argumentos internalistas expostos aqui. Ao invés da investigação crítica das contribuições dos externalistas para a resolução dos problemas levantados pelos argumentos contra a tese de que os únicos conteúdos relevantes são amplos, o presente trabalho ocupou-se, especificamente, de levantar os argumentos a favor da posição internalista, bem como de isolar algumas assunções mais relevantes desses argumentos. O objetivo era mostrar que, embora a posição vigente no debate atual acerca de conteúdos mentais tenda para o lado externalista, é importante não perder de vista as vantagens oferecidas pela posição internalista. No caso da causação mental, o argumento mostra que uma noção de conteúdo estreito é indispensável para o tipo de explicação causal (local) exigida pela psicologia cognitiva baseada em conteúdo de estados mentais. A noção de conteúdo estreito também é útil na captura do tipo de conteúdo inalterado ao qual temos acesso introspectivo. Finalmente, a posição internalista oferece soluções diretas a enigmas da racionalidade, como o enigma de Kripke sobre as crenças aparentemente contraditórias de Pierre. Tendo em vista, os argumentos contra o externalismo, é esperado que a plausibilidade da noção de conteúdo estreito tenha sido estabelecida no intuito de desenvolver uma noção viável de conteúdo estreito que evite os problemas mencionados anteriormente, como o da inefabilidade do conteúdo estreito e da possibilidade de ele poder não ser expressado por conceitos, uma vez que conteú- 
dos mentais precisam ser compartilhados, é difícil de imaginar como conteúdos individuados exclusivamente por propriedades intrínsecas do sujeito poderiam ser compartilhados.

A noção viável de conteúdo estreito poderia ser desenvolvida de muitas maneiras. ${ }^{2} \mathrm{O}$ papel das teorias que Putnam e Burge desenvolveram é o de resgatar a contribuição do ambiente do sujeito na determinação dos estados mentais. O internalismo "tradicional" é uma teoria que desconsidera os aspectos do ambiente na individuação de estados mentais. Somente por isso, a contribuição do externalismo de Putnam e Burge para a filosofia é das mais importantes. Como simplesmente ignorar a configuração externa do organismo na especificação de seus conteúdos mentais? As considerações feitas no presente trabalho tiveram o objetivo de mostrar que há necessidade de integrar a dependência ambiental do conteúdo a uma teoria que reconhece um núcleo viável de conteúdo estreito. Uma teoria do conteúdo mental que reconheça exclusivamente sua dependência de fatores externos parece dissociá-lo das relações racionais entre pensamentos e do papel que o pensamento desempenha na determinação das nossas ações. A conclusão, mais uma vez, é que qualquer teoria do conteúdo precisa reconhecer uma dimensão interna do pensamento e que somente ela poderia refletir os aspectos racionais e cognitvos que conectam pensamento e ação.

\section{Referência bibliográfica}

BURGE, T. Individualism and the Mental. Midwest Studies in Philosophy, Vol. 4, 1979, pp. 73-121.

CHALMERS, D.J. The Components of Content. In: CHALMERS, D.J. (org.). Philosophy of Mind: Classical and Contemporary Readings. Oxford: Oxford University Press, 2002. Citado de acordo com < http:// consc.net/papers/content.html>.

FODOR, J. Individualism and Supervenience. Psychosemantics. Cambridge: MIT Press, 1987, pp. 27-53.

2 Uma das soluções disponíveis na literatura seria a aplicação da semântica bidimensional ao problema do conteúdo mental. Ver Chalmers (2002) para a solução mencionada 
FODOR, J. A Modal Argument to Narrow Content. Journal of Philosophy, Vol. 88, No 1, 1991, pp. 5-26.

JACKSON, F. Reference and Description Revisited. Philosophical Perspectives, Vol. 32, suplemento 12, Language, Mind and Ontology, 1998a, pp. 201-218.

JACKSON, F. Narrow Content and Representation, or Twin Earth Revisited. Proceedings and Addresses of the American Philosophical Association, Vol. 77, No. 2, 2003, pp. 55-70.

JACKSON, F. Representation and Narrow Belief. Philosophical Issues, Vol. 13, No 1, 2004a, pp. 99-112.

KRIPKE, S. (1979). "A Puzzle about Belief." Em MARGALIT, A. (org.) (1979). Meaning and Use. D. Reidel.

MCGINN, C. Mental Content. Oxford: Basil Blackwell Inc, 1989.

PUTNAM, H. Meaning and Reference. Journal of Philosophy, Vol. 70, 1973, pp. 699-711.

PUTNAM, H. The Meaning of 'Meaning'. Em Gunderson, K. (org.). Language, mind and knowledge, pp. 131-193. Minneapolis: University of Minnesota Press. Reimpresso em Mind, Language and Reality: Philosophical Papers, Vol. 2, pp. 215-271. Cambridge: Cambridge University Press, 1975. 